\title{
Detection of LV function abnormality using temporal patterns of normalized wall thickness
}

\author{
Mai Wael ${ }^{2}$, El-Sayed Ibrahim ${ }^{1 *}$, Ahmed S Fahmy ${ }^{2}$ \\ From 18th Annual SCMR Scientific Sessions \\ Nice, France. 4-7 February 2015
}

\section{Background}

Global measures of cardiac function may not reflect subtle wall motion abnormalities. In such cases, assessment of regional cardiac wall motion is required, which is usually evaluated visually with highly subjective results. Automatic analysis techniques can be classified into intensity-based and contour-based methods with the latter category avoiding the image quality-related limitations in the first one. In this study, we present a contour-based technique for detecting wall motion abnormality based on studying the temporal pattern of normalized wall thickness.

\section{Methods}

Image datasets from 14 volunteers and 13 patients (4 with myocardium infarction, 5 with pulmonary hypertension; and 4 with myocardium hypertrophy) were used to train and test the proposed classifier. Three short-axis cine images were acquired at basal-, mid-,

and apical sites. All images were manually segmented to extract the epi- and endocardium. Each contour was resampled at equi-angular spaces to vectors of 60 -points in the mid and basal slices and 40-points in the apical slices. Regional temporal changes in wall thickness were extracted based on standard AHA 17-segment model. The extracted thickness pattern was normalized relative to average epicardial radius. The wall thickness values of all points within each segment were averaged to one value (Fig. 1).

The 1-fold leave-one-out method [1] was applied for training the classifier. Principal-component analysis was applied to find the directions of data variations and for dimensionality reduction. F1-score was used to select the proper number of principal-components. Naïve Bayes' classifier was applied to assign label to each segment (normal or abnormal). Slice abnormality was determined if slice contains two or more abnormal segments.

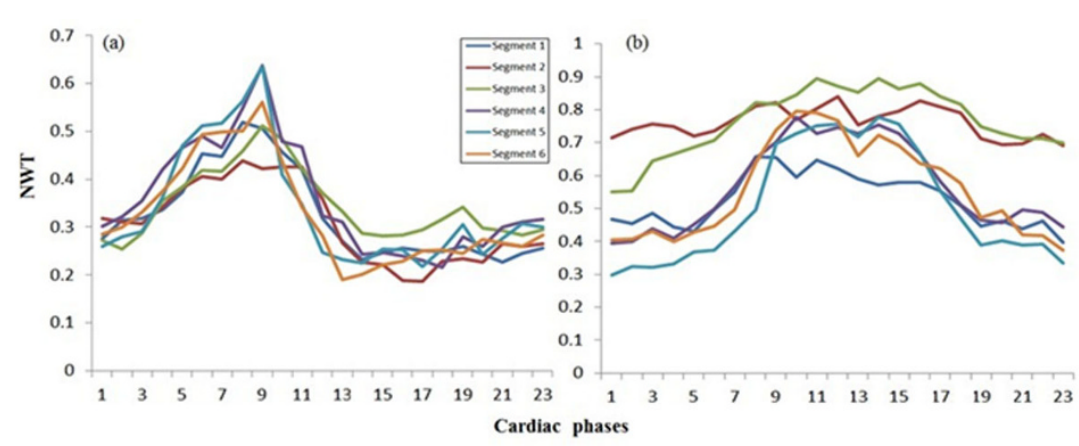

Figure 1 Normalized wall thickness (NWT) throughout the cardiac cycle for all six segments in a mid-ventricular short-axis slice from (a) normal (volunteer) and (b) patient with hypertrophy.

${ }^{1}$ University of Michigan, Ann Arbor, MI, USA

Full list of author information is available at the end of the article

(c) 2015 Wael et al; licensee BioMed Central Ltd. This is an Open Access article distributed under the terms of the Creative Commons 

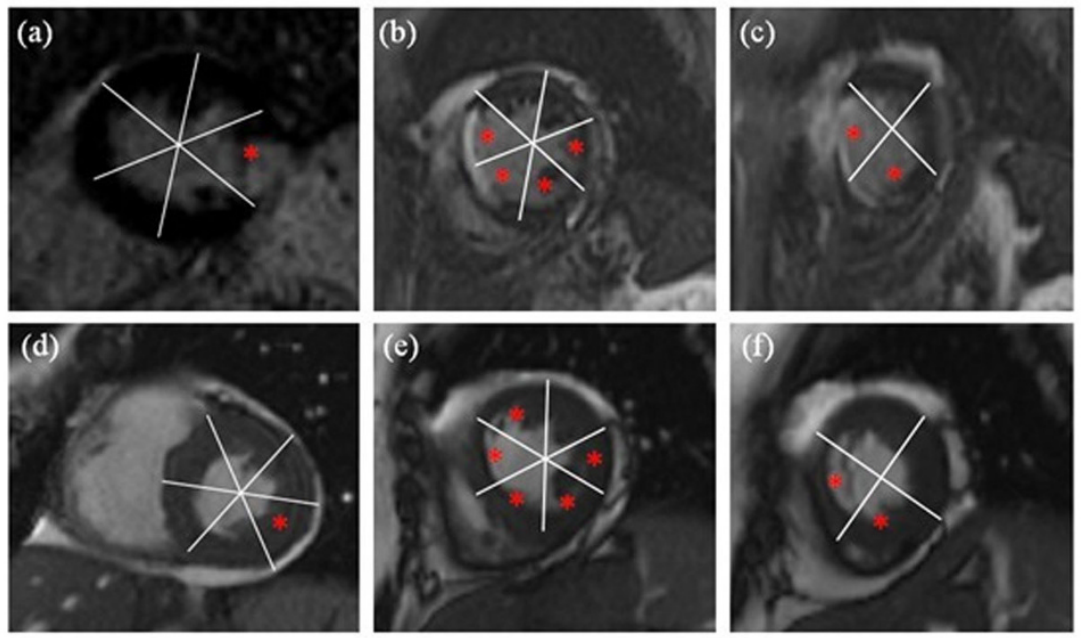

Figure 2 Comparison between infarcted regions using delayed-hyperenhancement MRI (a,b, and c) and regions with motion abnormality detected using the proposed method (d,e, and f).

\section{Results}

The highest F-score (highest accuracy) occurred when one principal-component was used, which captures $89 \%$ of all data variations. $100 \%$ true-negative and $70 \%$ truepositive were achieved for basal- and mid-slices and $70 \%$ true-positive for apical-slices. Higher specificity relative to sensitivity was recorded, which reflects that the algorithm's tendency for true identification of normal cases over abnormal cases. The overall system accuracy was $88 \%, 88 \%$, and $85 \%$ for basal, mid, and apical slices, respectively. Fig. 2 shows the resulting high agreement between the classifier results and ground-truth viability images.

\section{Conclusions}

The proposed method provides automatic assessment of regional myocardial abnormality in a segmental basis for each slice; therefore, it could be a valuable tool for automatic and fast detection of early signs of cardiac dysfunction from conventional untagged cine images.

\section{Funding}

N/A.

\section{Authors' details}

${ }^{1}$ University of Michigan, Ann Arbor, MI, USA. ${ }^{2}$ Nile University, Cairo, Egypt.

Published: 3 February 2015

\section{Reference}

1. Elisseeff A: "Leave-one-out error and stability of learning algorithms with applications". IOS Press 2002.
doi:10.1186/1532-429X-17-S1-P47

Cite this article as: Wael et al: Detection of LV function abnormality using temporal patterns of normalized wall thickness. Journal of Cardiovascular Magnetic Resonance 2015 17(Suppl 1):P47.

\section{Submit your next manuscript to BioMed Central} and take full advantage of:

- Convenient online submission

- Thorough peer review

- No space constraints or color figure charges

- Immediate publication on acceptance

- Inclusion in PubMed, CAS, Scopus and Google Scholar

- Research which is freely available for redistribution
Biomed Central 